\title{
Computação Aplicada à Educação Musical: desafios e perspectivas ao planejamento docente no contexto da Educação Inclusiva
}

\author{
Amanda Meincke Melo ${ }^{1}$, Carla Eugenia Lopardo ${ }^{2}$, Guilherme Moreira de Melo ${ }^{2}$ \\ ${ }^{1}$ Universidade Federal do Pampa (Unipampa) - Campus Alegrete \\ Av. Tiarajú, 810 - Ibirapuitã - 97.546-550 - Alegrete - RS - Brasil \\ ${ }^{2}$ Universidade Federal do Pampa (Unipampa) - Campus Bagé \\ Av. Maria Anunciação Gomes de Godoi, 1650 - Malafaia - 97.546-550 - Bagé - RS - \\ Brasil \\ \{amanda.melo, carla.lopardo\}@unipampa.edu.br, sai.guilherme@gmail.com
}

\begin{abstract}
The Music content is mandatory in Brazilian schools and should be taught in inclusive educational settings. However, there is lack of solutions to allow teachers of Music, with or without disability, identify and reuse didactic and musical material in their education planning in inclusive educational settings, which take students characteristics and needs into account as well as their own situation. Thus the effective use of Computer in Education is placed at risk. This paper aims at contributing to this scenario, pointing out ways to approach the challenge of effective use of Computer in Education, emphasizing teacher planning in Inclusive Music Education.
\end{abstract}

Resumo. O conteúdo de Música é obrigatório nas escolas brasileiras e deve ser oferecido em contexto educacional inclusivo. No entanto, faltam soluções que possibilitem ao professor de Música, com ou sem deficiência, identificar e reutilizar materiais didático-musicais para o seu planejamento em contextos educacionais inclusivos, que considerem as características e necessidades de seus alunos e a sua própria condição. Compromete-se, assim, a efetivação do uso de tecnologias digitais na Educação. Este artigo busca contribuir com esse cenário, apontando caminhos para lidar com o desafio da efetivação do uso das tecnologias digitais na educação, com ênfase no planejamento docente no contexto da Educação Musical Inclusiva.

\section{Introdução}

O ensino de Música, desde 2008, é considerado conteúdo curricular obrigatório da Educação Básica. Portanto, deve-se articular à Educação Inclusiva, que considera a Educação Especial uma modalidade transversal a todos os níveis, etapas e modalidades de ensino. Nesse cenário as tecnologias digitais têm importante papel a desempenhar.

Uma série de contribuições da Computação existe para atender a demandas da Educação Musical. Entretanto, observa-se que a adoção das tecnologias digitais na Educação Musical por professores com deficiência está comprometida pela forma incipiente como requisitos de acessibilidade ainda têm sido contemplados - ou deixam de ser contemplados - na produção de materiais didático-musicais e na organização 
desses materiais para que possam ser amplamente reutilizados. Além disso, aspectos específicos da Educação Musical podem ser mais bem explorados na catalogação de materiais didádico-musicais de modo a favorecer um melhor aproveitamento por professores da área, entre eles professores com deficiência.

Vislumbra-se como desafio, portanto, a efetivação do uso de tecnologias na educação, respeitando-se a multiplicidade das diferenças entre os integrantes de uma comunidade escolar. Em particular, tem-se em vista a contribuição da Computação à Educação Musical no processo de planejamento didático, proporcionando que professores, com ou sem deficiência, possam organizar suas aulas considerando as capacidades e as necessidades de seus alunos.

O artigo está organizado como segue. A Seção 2 colabora ao delineamento do desafio do ponto de vista da Educação Musical. A Seção 3 apresenta contribuições da comunidade de Informática na Educação para o domínio da Educação Musical, apontando para a possibilidade de contribuições da subárea Metodologias e Técnicas da Computação. A Seção 4 sugere um caminho para vencer o desafio com propostas que envolvem a colaboração de áreas como Engenharia de Software, Interação HumanoComputador, Semiótica Organizacional, Desenho Universal, Tecnologia Assistiva e Objetos de Aprendizagem (OA). Finalmente, são apresentadas as considerações finais deste artigo.

\section{A Educação e o Desafio}

O parecer CNE/CEB $n^{\circ}$ 12/2013, aprovado em 4 de dezembro de 2013, o qual estabelece as Diretrizes Nacionais para a operacionalização do ensino de Música na Educação Básica, define as bases para a implementação da Lei 11.769/08 que torna obrigatório o ensino de Música nas escolas como conteúdo, não exclusivo, da disciplina Artes. Este documento destaca a importância da presença da música no ambiente escolar determinando o compromisso que cada uma das esferas envolvidas deverá assumir, especificando as competências de cada setor (Escolas, Secretarias de Educação, Instituições de Ensino Superior, Ministério de Educação, Conselhos de Educação) nas diversas etapas e modalidades da inserção da música. Ainda, ao referir-se sobre a importância da presença da música no ambiente escolar e seus benefícios, o parecer salienta que "existem ligações específicas entre o estudo de Música e a habilidade de manipular informação tanto na memória de trabalho (usada para pensar), como na memória de longa duração (usada para arquivar os conteúdos aprendidos, os métodos e a experiência)", desta forma, "o estudo de Música impacta a aprendizagem de outras áreas do conhecimento, além de formar comportamentos de atenção que impulsionam e melhoram a cognição", promovendo, assim, a formação integral da criança (p. 6).

Com base neste parecer, conceitos como educação integral, interdisciplinaridade e inovação surgem como desafios para a área da Educação Musical, pois, como mencionado no documento, ela atua diretamente no cérebro estimulando a capacidade de decorar, de imitar, de reproduzir, de coordenar, de associar, de identificar, dentre outros aspectos relacionados à inteligência musical, área de estudo da neurociência; além de desenvolver a atenção executiva, necessária para formar memórias de qualquer área do conhecimento formal e de suas metodologias, influenciando indiretamente outras áreas do conhecimento. 
Além disso, a prática musical escolar contribui para o desenvolvimento do convívio social da criança e do jovem, estimulando a interação social e formação de identidade cultural, fortalecendo os vínculos entre os membros de uma comunidade. Uma das formas de comunicação que o cérebro humano utiliza para estabelecer relações com o mundo é a música, capaz de comunicar sentimentos e emoções que a fala não consegue transmitir. Portanto, a prática musical cria "condições especiais de comunicação, tais como aquelas entre e com as pessoas com deficiência (surdas, cegas, mudas, com síndromes, com alterações em seu desenvolvimento, patologias, paralisia cerebral, entre outros)" (p.6).

Nesse contexto, faz-se necessário remeter também à Política Nacional de Educação Especial na Perspectiva da Educação Inclusiva, de 2008, que objetiva "o acesso, a participação e a aprendizagem dos estudantes com deficiência, transtornos globais de desenvolvimento e altas habilidades/superdotação nas escolas regulares". Reitera, assim, o direito à educação em todos os níveis de ensino, sendo a educação especial uma modalidade transversal a todos os níveis, etapas e modalidades da educação. A escola atual, portanto, ao transformar-se para promover a educação inclusiva, evidencia ao professor a necessidade de formação e capacitação que o habilite a desenvolver sua prática num espaço de reconhecimento e de respeito às diferenças.

Esta também é uma necessidade do professor de Música, que precisa adaptar sua prática e aprimorar sua capacitação para oferecer aos alunos o ensino de Música, visando a proporcionar experiências musicais significativas a todos, indistintamente. É preciso ir além, garantindo a participação de todos os implicados nesse processo (ex.: professores, gestores, profissionais da educação, familiares etc.), indo ao encontro do Decreto 6.949/2009, que promulga a Convenção Internacional sobre os Direitos das Pessoas com Deficiência e, mais recentemente, da Lei 13.146/2015, que institui a Lei Brasileira de Inclusão da Pessoa com Deficiência (Estatuto da Pessoa com Deficiência).

A revisão da literatura na área da Educação Musical Inclusiva evidencia que grande parte dos trabalhos é voltada ao estudo da integração do aluno com deficiência na Educação Básica através do desenvolvimento de projetos interdisciplinares, contemplando também a possibilidade de articulação com a musicoterapia como área que abraça aspectos relacionados tanto à psicologia quanto à medicina. Esses trabalhos sugerem a inserção de recursos de Tecnologia Assistiva (TA) viabilizando a inclusão da pessoa com deficiência física na Educação Musical [Louro 2003]. Algumas pesquisas relatam experiências de músicos cegos na procura por subsídios para o ensino de Música, evidenciando as diversas dificuldades com as quais se deparam diante do acesso a materiais didáticos e ao perceberem as lacunas existentes na própria formação [Oliveira e Reily, 2014]. Nesse contexto, a Musicografia Braille se apresenta como uma técnica muito utilizada entre alunos e professores com deficiência visual, mas nem sempre accessível a todos. Por esse motivo ela representa também um desafio enquanto ensino-aprendizagem da própria técnica, sendo necessária maior difusão, a adaptação de materiais e a implementação de cursos que evite o autodidatismo em alunos e professores [Bonilha 2010][Tudissaky 2015].

No âmbito dos software para Educação Musical Inclusiva estão alguns programas voltados ao ensino de Música derivado da Musicografia Braille. Um exemplo disso é o software MUSIBRAILLE, mas existe um grande problema para os deficientes 
visuais: a escassa quantidade de obras transcritas para essa técnica [Souza 2013]. O software CROMOTMUSIC, por outro lado, explora o uso de mecanismos e dispositivos de vibração para a aprendizagem musical de crianças e jovens surdos, a partir de uma abordagem musicoterapêutica [Rodrigues 2015].

Além dos recursos mencionados, existem outras inovações que desafiam os limites da comunicação e expressão através da música. Entre os recursos criados pelo Drake Music (2016) - um centro de tecnologia musical da Inglaterra - estão o SOUNDBEAM 5 e o SKOOG. Enquanto o primeiro permite a expressão através do som usando apenas movimentos em interface com um controlador MIDI, o segundo apresenta uma interface musical - um cubo de espuma para plataforma iPad - que permite criar, interpretar e ouvir com acessibilidade e dinamismo expressivo-musical dados pelo seu Desenho Universal. Ambos foram testados com usuários com deficiência.

Ao analisar avanços nas pesquisas sobre Tecnologia Assistiva na área da Educação Musical, observa-se que os software voltados ao ensino de Música para pessoas com algum tipo de deficiência, seja esta física, visual, auditiva, intelectual ou múltipla, visam à aprendizagem de elementos da linguajem musical relacionados com a leitura e escrita de música e a apreciação musical, mas nenhum deles centra a sua atenção na relação e articulação entre os diferentes modos de fazer, ouvir e criar música a partir dos eixos organizacionais da área, nem nos processos de ensino-aprendizagem musical implícitos nessas práticas, necessários para o planejamento do professor ou aluno com algum tipo de deficiência. Apresenta-se, assim, uma situação que exige a existência de soluções que auxiliem na elaboração de materiais didáticos, na construção de planos de aula e na avaliação da prática musical em sala de aula, tanto para uso do professor como dos alunos inseridos em contexto educativo inclusivo. Esses aspectos se constituem atualmente como uma das principais lacunas que não foram vencidas pelos trabalhos visitados.

Para além da revisão de literatura apresentada, algumas questões, que partem da realidade em que está inserida uma estudante cega, matriculada Curso de Licenciatura em Música do Campus Bagé da Unipampa, também provocam a refletir sobre a efetivação do uso de tecnologias na educação no contexto da Educação Musical Inclusiva: Como esta estudante, em seu campo de estágio, daria aula sem enxergar para alunos que enxergam? Como uma pessoa cega ministraria aulas de teoria musical? De percepção musical? De instrumentos? Quais ferramentas tecnológicas estariam disponíveis para auxiliar estudantes em seus estágios? Onde encontrar informações sobre as tecnologias existentes para auxiliar em suas tarefas de docente? Como organizar em uma ferramenta os conteúdos que envolvem a Educação Musical em seus diferentes eixos organizacionais, garantindo sua acessibilidade universal?

Para o aluno estagiário ou o próprio professor de Música, com ou sem deficiência, ambos atuantes em sala de aula, portanto, é um desafio significativo pensar, criar, organizar, planejar e avaliar aulas, materiais e recursos didáticos em variados formatos que possibilitem conciliar suas capacidades com as capacidades e as necessidades da turma ou de alunos específicos.

Nesse cenário, as tecnologias digitais na educação desempenham papel fundamental e podem ser desenhadas para atender a todos na maior extensão possível, 
de acordo com o Desenho Universal, ou desempenhar o papel de recurso de Tecnologia Assistiva, promovendo funcionalidades e a autonomia de pessoas com deficiência [Melo 2014].

\section{A Computação e o Desafio}

Barvinks e Odakura (2012), ao abordarem o papel da Informática na Educação no contexto dos desafios educacionais para o Século XXI, apresentam desafios em que a Computação tem um papel a desempenhar, entre eles a centralização de Objetos de Aprendizagem ou links a esses, para uso livre de escolas e alunos, de modo que possam enriquecer a aprendizagem e auxiliar na superação de barreiras na aprendizagem. Sugerem que estruturas existentes, a exemplo do repositório RIVED do MEC, poderiam ser mais intensivamente adotadas, cuidando-se a atribuição de autoria dos objetos depositados. Os atuais repositórios de Objetos de Aprendizagem, em âmbito nacional, entretanto, não consideram características de acessibilidade desejáveis à promoção da Educação Inclusiva ou mesmo a especificidade da Educação Musical. Esta, além da organização de seus conteúdos e atividades por níveis de ensino, adotam eixos como ouvir, interpretar e criar, relevantes à organização e à recuperação de materiais didáticomusicais.

Ficheman et al. (2004) apresentam o portal EduMusical como um ambiente multimídia e interativo no qual alunos, professores e visitantes podem encontrar aplicativos para a aprendizagem musical. Fundamentam-se no modelo (T)EC(L)A, que trata do envolvimento direto com a música (ex.: Execução, Composição e Apreciação) e do conhecimento sobre a música (ex.: Técnica e Literatura). O portal, no entanto, foi implementado com a tecnologia Flash, sem evidências em sua página principal sobre a oferta de alternativas aderentes a padrões contemporâneos de acessibilidade, que favoreçam sua adoção irrestrita a pessoas com deficiência [Melo 2014].

Viana Junior e Castro-Filho (2005), baseados no Modelo Espiral de Desenvolvimento Musical e o Modelo C(L)A(S)P - ou (T)EC(L)A - recomendam um conjunto de categorias para a avaliação de software de Educação Musical, a saber: aquisição do conhecimento, processo de aprendizagem, aspectos auditivos, exemplos musicais, formas de intervenção e atividades musicais. Estas podem, ainda, serem subdivididas entre concepção tradicional e concepção construtivista, de acordo com a abordagem pedagógica adotada para o ensino da Música.

Ferreira et al. (2008) apresentam uma arquitetura para a recuperação personalizada de OA, ilustrando como exemplo de utilização uma aplicação voltada ao processo de aprendizagem de ritmos brasileiros. O enfoque está na adaptação de conteúdo, baseada nas interações aluno-sistema. Para isso, utilizam redes de Kohonen, ou mapas auto-organizáveis - um tipo de rede neural - em um protótipo desenvolvido com infraestrutura de software livre.

Pinhati e Siqueira (2015) propõem a Plataforma Mignone, que abrange diretrizes para a construção de OA e a especificação de um Ambiente Virtual de Aprendizagem (AVA) para facilitar a construção de Objetos de Aprendizagem e sua utilização em atividades de Educação Musical. O projeto da plataforma contempla especificidades do domínio da Educação Musical ao adotar como referência o modelo (T)EC(L)A para a 
produção de OA e a organização de atividades de Educação Musical. Entretanto, os autores não deixam claro como requisitos de acessibilidade e de usabilidade estão contemplados na proposta.

Pode-se mencionar, ainda, soluções para o contexto da Educação Musical, a exemplo do software Zorelha voltado ao desenvolvimento da percepção musical por crianças entre 4 e 6 anos [Jesus et al. 2010]; a proposta de uma interface musical tangível com tecnologia de Realidade Aumentada (RA), que pode ser usada como compositor musical, jogo de memória musical ou jogo de tempo coincidente musical, que foi avaliada com pessoas com Distrofia Muscular Duchenne e crianças com Paralisia Cerebral [Corrêa et al. 2012]; e a modelagem de um software para a Educação Musical de forma colaborativa, com auxílio do framework LUCID, mediada pela plataforma Amadeus [Venega e Sousa 2012].

Em síntese, a análise de trabalhos publicados nos eventos da comunidade Brasileira de Informática na Educação como o DesafIE - Workshop de Desafios da Computação Aplicada à Educação, o SBIE - Simpósio Brasileiro de Informática na Educação e o WIE - Workshop de Informática na Escola, além da RBIE - Revista Brasileira de Informática na Educação, permite mencionar uma série de contribuições para a área da Educação Musical, incluindo a publicação na web de materiais didáticomusicais, a organização de AVA, diretrizes para a produção de OA e a avaliação de software, a oferta de software para o ensino da Música, para o exercício da percepção musical, para a expressão e a criação musical, para a o processo de reabilitação, a formação de professores de Música, entre outros.

A efetivação do uso das tecnologias digitais na Educação para o planejamento docente no contexto da Educação Musical Inclusiva pode se beneficiar, portanto, da aplicação de Metodologias e Técnicas da Computação que contemplem adequadamente o domínio da Educação Musical, observem princípios de acessibilidade e contribuam à organização e à recuperação de materiais educacionais digitais considerando aspectos desse domínio e características de acessibilidade, além de padrões existentes para a organização e recuperação de materiais educacionais digitais. Envolve, deste modo, contribuições de áreas como Engenharia de Software, Interação Humano-Computador, Desenho Universal e Objetos de Aprendizagem.

\section{Proposta: Um Caminho para Vencer o Desafio}

$\mathrm{Na}$ atuação interdisciplinar e interprofissional entre as áreas da Educação Musical e da Computação, torna-se possível contribuir à efetivação do uso das tecnologias digitais na Educação para o planejamento docente no contexto da Educação Musical Inclusiva. Propõe-se, assim:

1. A construção de conhecimento sobre o domínio da Educação Musical, suas partes interessadas, além dos requisitos trazidos pela Educação Inclusiva, com auxílio de métodos e técnicas da Computação, integrando conhecimentos e procedimentos da Engenharia de Software, da Interação Humano-Computador e da Semiótica Organizacional [Melo et al. 2012][Melo 2014];

2. Identificação, classificação e catalogação de matérias didático-musicais, considerando-se aspectos como níveis de ensino, eixos da Educação Musical 
[Colwell 1992], características de acessibilidade e padrões para a catalogação de Objetos de Aprendizagem [Braga 2014];

3. Incentivo à construção de materiais didático-musicais com Desenho Universal;

4. Incentivo à produção de recursos de Tecnologia Assistiva voltados à Educação Musical;

5. Desenvolvimento de repositórios de OA, com Desenho Universal, que contemplem adequadamente o domínio da Educação Musical, mas que também possam ser integrados a outros repositórios [Braga 2015][Melo 2014];

6. Desenvolvimento de espaços de colaboração, com Desenho Universal, para o fazer docente em Educação Musical, em rede, contemplando aspectos como planejamento, práticas didático-musicais e avaliação.

Desse modo, vislumbra-se um caminho possível para a Computação contribuir à Educação Musical no processo de planejamento didático, proporcionando que professores, com ou sem deficiência, possam organizar suas aulas considerando as capacidades e as necessidades de seus alunos em perspectiva inclusiva.

\section{Considerações Finais}

Este artigo problematizou o uso de tecnologias digitais no contexto da Educação Musical Inclusiva no processo de planejamento docente, que também deve considerar professores com deficiência como usuários dessas tecnologias. Uma série de soluções foi apresentada no contexto da Educação Musical, mas essas não contemplam adequadamente o planejamento docente amplamente acessível.

Metodologias e Técnicas da Computação podem ser colocadas a favor desse desafio, para a melhor compreensão do domínio da Educação Musical Inclusiva, para a organização e o desenvolvimento de materiais didático-musicais acessíveis, para apoiar professores no planejamento didático que contemple amplamente a todos, inclusive o próprio professor. Para isso, faz-se necessária a organização de iniciativas que alinhem a colaboração interdisciplinar e interprofissional entre as áreas da Educação Musical e da Computação.

Transcende-se, assim, à aplicação de normas técnicas de acessibilidade, envolvendo também o alinhamento de referenciais e de práticas de pesquisa, a análise e a revisão de práticas, a identificação e a avaliação de recursos, a concepção de novas tecnologias digitais, além da organização em rede de profissionais da Educação Musical.

\section{Agradecimentos}

Às acadêmicas Rosane de Fraga, da Licenciatura em Música, e Lisiane dos Santos da Rosa, do Bacharelado em Ciência da Computação, pelas importantes contribuições ao desenvolvimento do projeto de pesquisa, em andamento, "Educação Musical Inclusiva mediada por Tecnologias Digitais Acessíveis”.

\section{Referências}

Barvinski, C. A., Odakura, V. V. A. "Desafios educacionais para o Século XXI e o papel da Informática na Educação”, DesafIE 2012, SBC, Brasil. 
Bonilha, F. F. G. (2010), Do toque ao som: o desafio da Musicografia Braille como um caminho para a educação musical inclusiva, Unicamp (Tese de Doutorado).

Braga, J. (2014), Objetos de Aprendizagem volume 1 - introdução e fundamentos, Editora UFABC.

Braga, J. (2015), Objetos de Aprendizagem volume 2 - metodologia de desenvolvimento, Editora UFABC.

Brasil (2008) "Lei n. 11.769, de 18 de Agosto de 2008", http://www.planalto.gov.br/ ccivil_03/_ato2007-2010/2008/lei/111769.htm

Brasil (2009) "Decreto n. 6949, de 25 de Agosto de 2009", http://www.planalto.gov.br/ ccivil_03/_ato2007-2010/2009/decreto/d6949.htm

Brasil (2015) "Lei n. 13.146, de 6 de Julho de 2015", http://www.planalto.gov.br/ ccivil_03/_Ato2015-2018/2015/Lei/L13146.htm

CNE/CEB (2013) "Diretrizes Nacionais para a operacionalização do ensino de Música na Educação Básica", http://portal.mec.gov.br/index.php?option=com_docman\& view=download\&alias=14875-pceb012-13\&category_slug=dezembro-2013pdf\&Itemid=30192

Corrêa, A. G. D., Ficheman, I. K., Lopes, R. D. "O Fazer Musical de Pessoas com Deficiência: as novas tecnologias propiciando a inclusão", SBIE 2012, SBC, Brasil.

Colwell, R. (1992), Handbook of research on music teaching and learning, Schirmer.

Drake Music (2016?), http://www.drakemusic.org/

Ficheman, I. K., Lopes, R. D., Krüger, S. E., Bassani Neto, O. "PORTAL EDUMUSICAL: Telemática aplicada à Educação Musical”, SBIE 2004, SBC, Brasil.

Jesus, E. A., Uriarte, M. Z., Raabe, A. L. A. (2010). Zorelha: um objeto de aprendizagem para auxiliar o desenvolvimento da percepção musical em crianças de 4 a 6 anos. In Revista Brasileira de Informática na Educação, p. 91-105. SBC.

Louro, V. S. (2003), As adaptações a favor da inclusão do portador de deficiência física na educação musical: um estudo de caso, Unesp (Dissertação de Mestrado).

MEC/SECADI (2008) "Política Nacional de Educação Especial na Perspectiva da Educação Inclusiva", http://portal.mec.gov.br/arquivos/pdf/politicaeducespecial.pdf

Melo, A. M. (2014) “Acessibilidade e Inclusão Digital em Contexto Educacional”,

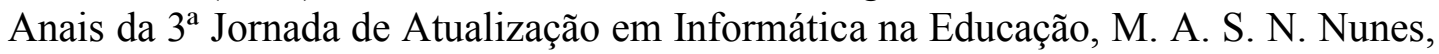
E. M. Rocha, Brasil, Sociedade Brasileira de Computação, p. 1-41.

Melo, A. M., Saldanha, J. F., Wernz, M. C. G. (2012) "Desafios à pesquisa em Computação em contexto educacional - qualidade no uso de objetos de aprendizagem em perspectiva", DesafIE 2012, SBC, Brasil.

Oliveira, L. A. C., Reily, L. H. (2014). Relatos de músicos cegos: subsídios para o ensino de música para alunos com deficiência visual. In Revista Brasileira de Educação Especial, p. 405-420. 
Pinhati, F. Siqueira, S. W. M. (2015). Plataforma Mignone: Ambiente Virtual de Aprendizagem e Objetos de Aprendizagem Especializados para a Educação Musical. In Revista Brasileira de Informática na Educação, p. 1-17. SBC.

Rodrigues, I. O. (2015), Os efeitos da musicoterapia através do software Cromotmusic em aspectos sensoriais, emocionais e musicais de crianças e jovens surdos : ensaio controlado randomizado, UFRGS (Dissertação de Mestrado).

Souza, L. S. (2013), O uso do software Musibraille no processo de ensino-aprendizagem musical de alunos com deficiência visual: da transcrição à utilização pedagógica, UFPB (Trabalho de Conclusão de Curso).

Tudissaky, S. E. (2015), Ensino de música para pessoas com deficiência visual, Unesp (Dissertação de Mestrado).

Venega, V. S., Sousa, W. P. "Modelagem Participativa de um Software de Ensino Musical”, DesafIE 2012, SBC, Brasil.

Viana Júnior, G. S., Castro-Filho, J. A. "Avaliação de Software para o Ensino de Música: reconhecendo a singularidade do discurso musical”, WIE 2005, SBC, Brasil. 